\title{
Data Descriptor \\ Deceptive Content Labeling Survey Data from Two U.S. Midwestern Universities
}

\author{
Ryan Suttle ${ }^{1}$, Scott Hogan ${ }^{1}$, Rachel Aumaugher ${ }^{1}$, Matthew Spradling ${ }^{1}{ }^{\circledR}$, Zak Merrigan ${ }^{2}$ and Jeremy Straub ${ }^{2, *}$ \\ 1 Department of Mathematics \& Applied Sciences, University of Michigan-Flint, Flint, MI 48502, USA; \\ rsuttle@umich.edu (R.S.); richarho@umich.edu (S.H.); raumaugh@umich.edu (R.A.); \\ mjspra@umich.edu (M.S.) \\ 2 Department of Computer Science, North Dakota State University, Fargo, ND 58102, USA; \\ zak.merrigan@ndsu.edu \\ * Correspondence: jeremy.straub@ndsu.edu; Tel.: +1-(701)-213-8196
}

\begin{abstract}
Intentionally deceptive online content seeks to manipulate individuals in their roles as voters, consumers, and participants in society at large. While this problem is pronounced, techniques to combat it may exist. To analyze the problem and potential solutions, we conducted three surveys relating to how news consumption decisions are made and the impact of labels on decision making. This article describes these three surveys and the data that were collected by them.
\end{abstract}

Dataset: https:/ /doi.org/10.17632/9ynrfz24cp.1

Dataset License: CC-BY-NC-ND.

check for updates

Citation: Suttle, R.; Hogan, S.; Aumaugher, R.; Spradling, M.; Merrigan, Z.; Straub, J. Deceptive Content Labeling Survey Data from Two U.S. Midwestern Universities. Data 2022, 7, 26. https://doi.org/ $10.3390 /$ data7030026

Academic Editors: Gianni Costa, Riccardo Ortale and

Francesco Bonchi

Received: 15 November 2021

Accepted: 18 February 2022

Published: 22 February 2022

Publisher's Note: MDPI stays neutral with regard to jurisdictional claims in published maps and institutional affiliations.

Copyright: () 2022 by the authors Licensee MDPI, Basel, Switzerland. This article is an open access article distributed under the terms and conditions of the Creative Commons Attribution (CC BY) license (https:// creativecommons.org/licenses/by/ $4.0 /)$.
Keywords: fake news; media labeling; misinformation; perceptions of labeling online content; deliberately deceptive content

\section{Summary}

The so-called "fake news" phenomenon is cause for concern. Numerous indicators of the problem exist. Perhaps the first is the term "fake news" itself, which to some indicate deceptive content [1], while others use the term to refer to "discount and discredit ideologically uncongenial media sources" [2].

Irrespective of what it is called, deceptive online content is prolific. Over half of Americans have reported getting at least some news online, with many reporting having believed fake news articles in the past [3]. The impact of fake news across society has been demonstrated. The "pizza gate" incident showed how deceptive content could be used to manipulate individuals to taking actions [4]. The 2016 election demonstrated the impact of deceptive content on politics and elections-it is projected that Americans consumed one to three fake news stories per week in the weeks leading to the election [5]. This content originated from both foreign and domestic sources, leading to concern about foreign influence; however, reports suggest that the results of foreign influence was "minimal" [6]. These problems are not just in the United States-South Korea experienced deceptive online content interference in its 2017 election [7,8], and numerous other examples outside of the United States exist (e.g., see $[9,10])$.

Deceptive content online has many uses; however, in many cases, it seeks to misinform the public and manipulate their actions or opinions [11]. The ability for parties to directly and precisely target and manipulate the actions of individuals is very problematic. It threatens key democratic processes, such as voting [12]. Individuals can be swayed to listen to and vote for one candidate or another. Additionally, deceptive content can be used to seed distrust in the systems and processes that underlie elections and to reduce election participation [13]. 
The impacts of deceptive online content, however, go far beyond voting. Its impact has been demonstrated in medicine [14], providing societal power [15] and even inciting violence [14], among other areas. It is changing the public's perception of traditional news sources [16]. It has been shown to have a disproportional impact to some other types of new content [17], and is also readily spread [18]. Marchi [19] notes that it is having a pronounced impact, in particular, on teenagers, causing them to question the concept of "journalistic 'objectivity"” altogether.

A variety of prospective solutions have been proposed, which include government regulation [20], market-based solutions [21], education [22], warning or labeling content [23,24], and technological interventions [20].

Three studies were conducted to investigate the nature of the problem and potential solutions to it, which were the basis for the analysis presented in [25]. This article describes data from the three surveys that were conducted. The first survey solicited respondents ${ }^{\prime}$ views on deceptive online content, how individuals make news consumption decisions, and steps that can be taken to mitigate its impact. The second and third surveys solicited respondents' views on labeling techniques that may be effective at combating intentionally deceptive online content. An example of one such label is presented in Figure 1. Notably, while many proposed solutions for content labeling are automated (e.g., [26]), several of the labels evaluated in the data presented herein would could be used with either automatically or manually (see, e.g., [27]) applied labels that could be created using a variety of different paradigms of identification mechanisms. This paper describes the data that was collected, which served as the basis for [25]. In addition to what was previously described in [25], this paper includes the release of the survey blank, facilitating reuse of the survey, and the complete dataset, facilitating different forms of analysis beyond those conducted by the authors in [25].

\section{Trouble at High Speed West Middle School}

High Speed West Middle School in deadlock due to boys refusing to say the word "hello", opting only to refer to people as "Gamers." 1 week ago

Title: Trouble at High Speed West Middle School Author: Michael Scott

Fact: $73 \%$

Opinion: $27 \%$

Emotion: 35

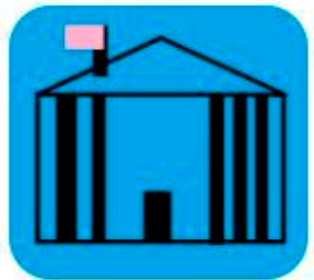

Authority: $2 / 10$

Viral: True

Topicality: $3 / 10$

Reading level: 12 th grade

Technicality: $2 / 10$

Figure 1. Example of a content label [25], using categories proposed by Fuhr et al. [28].

\section{Background}

Deceptive content is a pronounced problem for which a wide variety of solutions have been proposed, ranging from government regulation [20] to warning or labeling content $[23,24]$ to market-based solutions [21]. Because of its societal impact, it has been a subject of significant scholarly focus $[17,29]$ across numerous fields. One area of focus has been on the use of labeling to mitigate deceptive content's effect and spread.

\subsection{Labeling Online Content}

In response to the problem, online platforms such as Facebook [30], Twitter [31], and YouTube [32] have attempted different approaches to mitigate its effects and reduce its ability to spread. To this end, social media companies label some content. However, it is not clear what the impact of these labels are. Various researchers have studied ideas such as labeling [33], as well as their impact on people's recognition, detection, or sharing of deceptive online content [34-37]. Seo, Xiong, and Lee [38], for example, evaluated labeling 
media with simple warning labels. Labeling is not unique to online content. It has been proposed or used for numerous other products. An extended discussion of this is presented in [39].

\subsection{Content and Other Labeling Offline}

Several examples of offline content labeling exist. These include the MPAA and V-Chip ratings that warn about content in movies and television programs. These systems [40-42] primarily focus on the age appropriateness of the content as opposed to types of content; however, in some cases, they include a description of the reason that the rating was assigned.

One of the most familiar forms of labels, to many consumers, are the labels found on food. These labels inform consumers about the nutritional content of food [43] and have been shown to impact consumer behavior [44]. Because of their efficacy they are used in numerous countries (e.g., [45,46]).

Food nutrition labels have also served as the basis for other types of product labeling. Similar labels are also used for providing key information about light bulbs and appliances. Figure 2, for example, shows an example of a U.S. energy guide facts label. Across label types, significant focus has been placed on making sure that consumers can understand and use the information presented on the labels $[47,48]$.

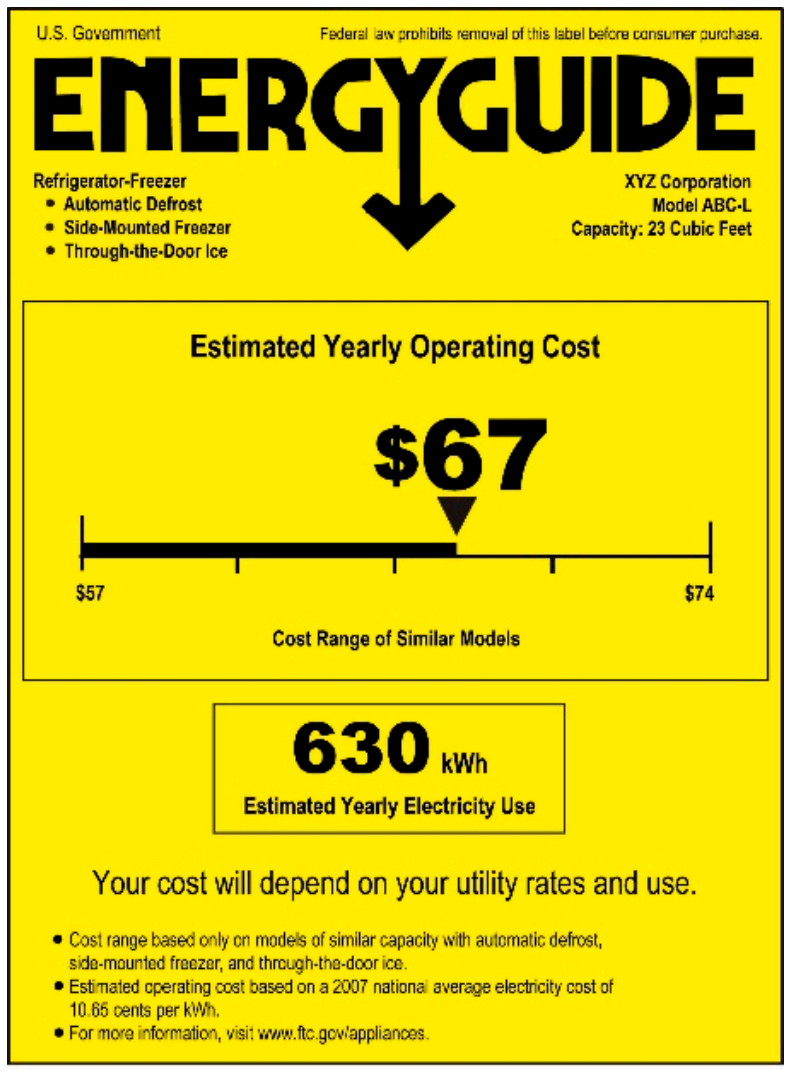

Figure 2. Energy guide label format [49].

In some cases, however, such as with the warning for wine (shown in Figure 3), labels go beyond simply providing information to provide a warning if a product poses danger to the consumer. Notably, deceptive online content ranges in severity. Thus, in some cases, content may merit a nutrition facts style label, while in others, a warning style one may be more appropriate. Understanding consumers perception of labels and the impact of their incorporation is the key focus of this study. 


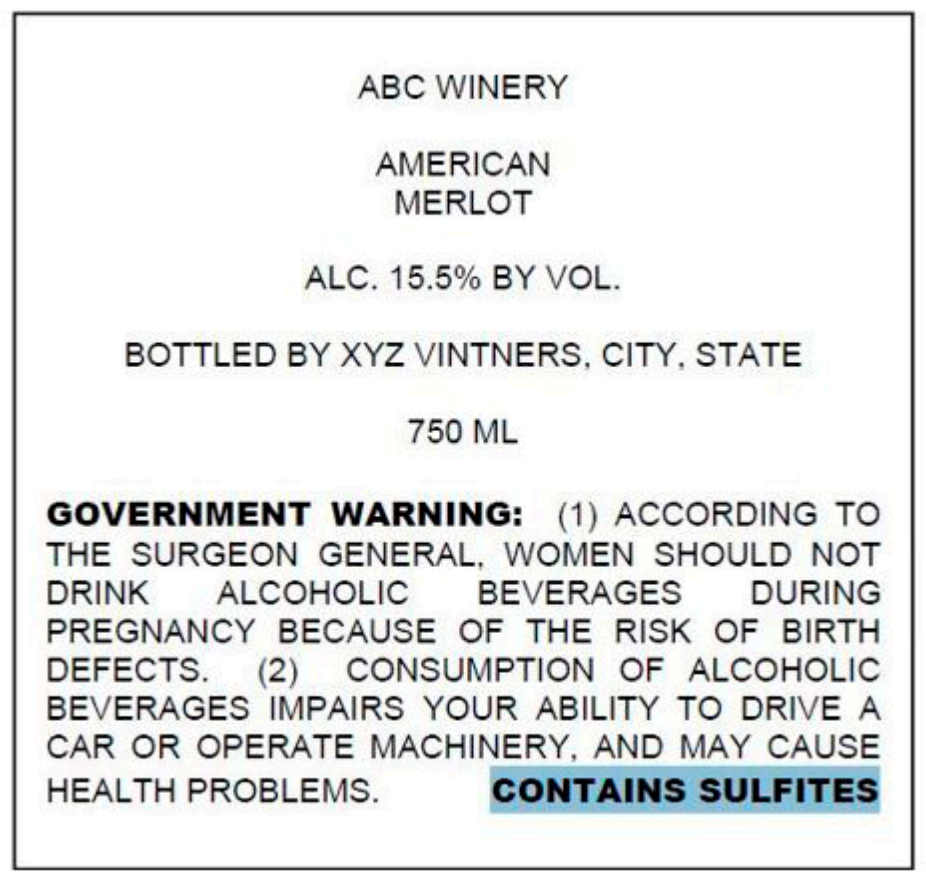

Figure 3. Alcoholic Beverage Labeling Act warning labels [50].

\section{Data Description}

Data were collected across three surveys, which were sent out concurrently. This section describes the three surveys and the data that they collected. It also discusses collection location population characteristics and respondent demographic characteristics.

\subsection{First Survey}

The first survey asked respondents questions regarding the impact of certain factors on their news consumption decision making and their perception of others' decision making. For each factor, respondents were asked three questions:

Consider your personal perceptions of trustworthiness and credibility of a news article. How much of an impact does the publisher of an article have on your personal perceptions of trustworthiness and or credibility of an article?

Consider your beliefs about the perceptions of others. How much of an impact do you believe the publisher of an article has on most people's perception of the trustworthiness and or credibility of an article?

If you were acting in an ideal manner, to what extent do you believe the publisher of an article should impact your perception of the trustworthiness and or credibility of an article?

For each question, respondents were asked to select one of five responses to characterize the impact of the particular factor on their and others decision making:
- A great deal
- A lot
- A moderate amount
- A little
- None at all

Respondents were also asked three demographic questions that collected details regarding their age, income level and education level. The full text of the first survey questions is presented in a Supplemental File.

\subsection{Second Survey}

The second survey asked respondents a number of questions about their past interactions with social media and deceptive content. Questions included "have you ever seen a social media post with a warning label?", "has a warning label ever been attached to a post that you have made?", and "do you think that social media and news websites should 
place warning labels on potentially misleading or false information?". In a second section, respondents were shown potential informational labels for social media posts (such as the label shown in Figure 1) and asked questions about their perception of the label. For each label, respondents were asked: "would you find this label helpful?"; "would you find this label annoying?"; "would you review this label when viewing news articles on social media?"; "do you think others would review this label when viewing news articles on social media?"; "do you think this label would be useful for judging the trustworthiness of news articles?"; and "when viewing the label, how easy was it to view and understand the information contained within it?". Respondents were also asked to compare label types and express their preferences between them. As with the first survey, respondents were asked demographic questions regarding their age, income level, and education level. The full text of the second survey questions is presented in a Supplemental File.

\subsection{Third Survey}

The third survey asked questions very similar to the second one. Like the second survey, it started with similar general questions regarding respondents' past interactions with social media and deceptive content. It then asked similar questions about several labels. Unlike the second survey, the third survey focused on warning labels (as opposed to informational ones). The questions asked about each label were "would you find this label helpful?"; "would you find this label annoying?"; "would you review this label when viewing news articles on social media?"; "do you think others would review this label when viewing news articles on social media?"; "do you think this label would be useful for mitigating the effects of articles that could potentially be damaging?"; and "when viewing the label, how easy was it to view and understand the information contained within it?". Like with the other surveys, respondents were asked demographic questions about their age, income level, and education level. The full text of the third survey questions is presented in a Supplemental File.

\subsection{Collection Location Characteristics}

The two cities and universities (which largely serve regional populations) have very different demographic characteristics, adding another dimension to the analysis and comparison of the responses from the two universities.

It is worth noting that universities may have different demographics from the cities that they are based in. In many cases, faculty come from other areas of the country or world to take university positions and, thus, the faculty have dissimilar demographics to the university's host city or region. Staff, on the other hand, are typically hired from within the region and, thus, are more likely to have region-similar demographic characteristics. For both of the universities studied, the student population is primarily drawn from the local region. Regional characteristics are presented below, for reference.

Flint, Michigan, where the University of Michigan-Flint is located, had a 2019 population of 96,559 and a poverty rate of $38.8 \%$, according to DataUSA [51]. Flint's median household income was USD 28,824 in 2019, and between 2018 and 2019, the city experienced a small population decline $(0.62 \%)$ and enjoyed a $4.03 \%$ increase in median household income. The city's three largest ethnic groups are "Black or African American (NonHispanic)" (53.2\%), "White (Non-Hispanic)" (36.9\%), and "Two+ (Non-Hispanic)" (4.54\%). The largest college or university in the city is the University of Michigan-Flint, which awarded 1550 degrees in 2019. The majority of Genesee County, Michigan (the county in which Flint is located) voters (52.3\%) selected the Democratic Party candidate in 2016.

Fargo, North Dakota, where North Dakota State University is located, had a population of 121,889 and a poverty rate of $13.2 \%$ in 2019, according to DataUSA [52]. The city's median household income was USD 55,551 in 2019, and it enjoyed a $1.4 \%$ increase in population and a $4.21 \%$ increase in median household income between 2018 and 2019. The city's three largest ethnic groups are "White (Non-Hispanic)" (82.7\%), "Black or African American (Non-Hispanic)" (6.98\%), and "Asian (Non-Hispanic)" (3.4\%). The largest college 
or university in Fargo is North Dakota State University, which awarded 3259 degrees in 2019. The most votes (49.3\%) in Cass County, North Dakota (the county in which Fargo is located), were cast for the Republican Party candidate in 2016.

Key demographic characteristics of respondents (such as age, education level, and income level) are included in the dataset. These could be used to support oversampling and stratification-based techniques to make inferences about the population.

\subsection{Respondent Characteristics}

Respondents were composed of students, faculty, and staff at two midwestern United States universities: the University of Michigan-Flint (University A) and North Dakota State University (University B). On the basis of the age, education, and income distributions, we found that most participants were students; however, a number of faculty and/or staff participated as well. Significantly more respondents from the 18-29 age group participated, as compared to any other group (comprising approximately $75 \%$ of respondents). Income and education levels were similarly skewed towards student demographics. Table 1 presents the age distribution of survey respondents. Tables 2 and 3 present the income and education level distributions of respondents, respectively.

Table 1. Ages of respondents to surveys.

\begin{tabular}{|c|c|c|c|c|c|c|}
\hline Survey & University & $18-29$ & $30-39$ & $40-49$ & $50-59$ & 60 or More \\
\hline \multirow[t]{2}{*}{ Survey 1} & $\begin{array}{c}\text { University } \\
\text { A }\end{array}$ & 27 & 8 & 4 & 1 & 1 \\
\hline & $\begin{array}{c}\text { University } \\
\text { B }\end{array}$ & 34 & 8 & 5 & 0 & 0 \\
\hline \multirow[t]{2}{*}{ Survey 2} & $\begin{array}{c}\text { University } \\
\text { A }\end{array}$ & 20 & 7 & 4 & 1 & 1 \\
\hline & $\begin{array}{c}\text { University } \\
\text { B }\end{array}$ & 22 & 6 & 5 & 0 & 0 \\
\hline \multirow[t]{2}{*}{ Survey 3} & $\begin{array}{c}\text { University } \\
\text { A }\end{array}$ & 17 & 5 & 2 & 1 & 1 \\
\hline & $\begin{array}{c}\text { University } \\
\text { B }\end{array}$ & 20 & 4 & 3 & 0 & 0 \\
\hline
\end{tabular}

Table 2. Income levels (in USD) of respondents to surveys.

\begin{tabular}{|c|c|c|c|c|c|c|c|c|c|}
\hline Survey & University & $\begin{array}{l}\$ 20,000 \\
\text { or Less }\end{array}$ & $\begin{array}{c}\$ 20,000 \\
\text { to } \$ 39,999\end{array}$ & $\begin{array}{c}\$ 40,000 \\
\text { to } \$ 59,999\end{array}$ & $\begin{array}{c}\$ 60,000 \\
\text { to } \$ 79,999\end{array}$ & $\begin{array}{c}\$ 80,000 \\
\text { to } \$ 99,999\end{array}$ & $\begin{array}{c}\$ 100,000 \\
\text { to } \$ 119,999\end{array}$ & $\begin{array}{c}\$ 120,000 \\
\text { to } \$ 139,999\end{array}$ & $\begin{array}{l}\$ 140,000 \\
\text { or More }\end{array}$ \\
\hline \multirow[t]{2}{*}{ Survey 1} & University A & 6 & 3 & 6 & 2 & 4 & 4 & 4 & 3 \\
\hline & University B & 9 & 11 & 8 & 1 & 1 & 1 & 2 & 5 \\
\hline \multirow[t]{2}{*}{ Survey 2} & University A & 6 & 2 & 5 & 1 & 4 & 4 & 2 & 2 \\
\hline & University B & 6 & 6 & 8 & 1 & 0 & 1 & 2 & 3 \\
\hline \multirow[t]{2}{*}{ Survey 3} & University A & 6 & 2 & 3 & 1 & 1 & 3 & 2 & 2 \\
\hline & University B & 4 & 5 & 7 & 0 & 0 & 1 & 2 & 2 \\
\hline
\end{tabular}

Table 3. Education levels of respondents to surveys.

\begin{tabular}{ccccccc}
\hline Survey & University & $\begin{array}{c}\text { High School Degree or } \\
\text { Equivalent }\end{array}$ & $\begin{array}{c}\text { Some College } \\
\text { (No Degree) }\end{array}$ & $\begin{array}{c}\text { Associate's } \\
\text { Degree }\end{array}$ & $\begin{array}{c}\text { Bachelor's } \\
\text { Degree }\end{array}$ & $\begin{array}{c}\text { Master's Degree or } \\
\text { More }\end{array}$ \\
\hline Survey 1 & University A & 0 & 22 & 4 & 12 & 4 \\
& University B & 1 & 13 & 6 & 12 & 11 \\
Survey 2 & University A & 0 & 16 & 3 & 7 & 4 \\
& University B & 0 & 10 & 2 & 3 & 7 \\
Survey 3 & University A & 1 & 12 & 3 & 7 & 7 \\
& University B & 0 & 10 & 5 & 7 \\
\hline
\end{tabular}




\section{Methods}

The survey was developed and reviewed by college students and faculty. It was also reviewed to validate that all survey questions were being understood as intended by members of the target participation demographics.

The survey data were collected using Qualtrics survey administration software. Links were emailed to research participants mailing lists (containing most faculty, staff, and students, except for those who have previously opted out) at the University of MichiganFlint and North Dakota State University in 2021. In each case, an initial email and a reminder email was sent out. All surveys were left open for responses for approximately two weeks. Respondents were free to complete the survey from any location of their choice, and no time limitation was applied to completion. Respondents were free to answer all, none, or only some of the questions. While it seems likely that some respondents may have answered two or all three surveys, no personally identifying data were collected to facilitate correlation.

\section{Data Processing}

After the surveys were completed, the data were reviewed to remove responses with invalid data or where the respondents answered no or only a minimal number of questions (such as only the consent question, or the consent question and next screen of questions). Additionally, the surveys were reviewed to remove any potential inadvertently entered personal identifying information. The survey data were then exported to Excel and comma separated value (CSV) files.

\section{Quality Control}

Several forms of quality control mechanism were used during the collection and processing of these data. First, the invitation to participate in the survey was set to mailing lists of individuals affiliated with the two universities, and therefore all invited participants were known to be members of the universities.

Second, all responses were reviewed, and a limited number of responses that were missing substantive amounts of data, failed to answer consent questions, or were lacking responses for key demographic details were not included in the dataset. Third, as part of the analysis presented in [25], the data were assessed for statistical significance and it was demonstrated for multiple conclusions that were presented in that paper, showing that there were sufficient data to draw conclusions from. Fourth, the analysis presented in [25] also demonstrated that trends and commonalities were present in the data and that measured changes were logical. All of these serve to validate and increase confidence in the dataset.

\section{User Notes}

Due to the age, income, and education distributions, stratified analysis techniques may be most useful. Considering data as belonging to the student versus non-student demographic groups may also be useful for analysis. The demographic differences between the areas housing the two universities also made comparisons between these two groups of particular interest, albeit with the limitations and considerations discussed in Section 3.4.

\section{Conclusions and Future Work}

This article has described a dataset that can be utilized to answer questions regarding perceptions of deceptive content, content sources, and warning labeling approaches. The dataset is composed primarily of students and contains data from two universities from different locations in the United States with different regional and student demographics.

Using the data presented herein, future researchers can analyze specific cross-question correlations of interest. This dataset could also be augmented via additional data collection (e.g., at another college or university) using the provided survey templates and compared with the data from the two existing schools. 
These data consider respondents' perceptions of issues with deceptive content, how they interact with it, and how they would respond to warning labels. Thus, these data are informative regarding both manually generated and automated warning systems. A manual or automated system based on fact checking with reliable sources would, of course, be a highly desirable solution. However, given the pressing nature of the problem and the lack of an immediately feasible solution of this type, other approaches must also be considered. Irrespective of how article reliability data are obtained, it must be presented to the user, which is the focus of this dataset.

Irrespective of the presentation format used, the perceptions of individuals regarding how to identify and classify misinformation may not necessarily match the reality of what works in practice. When there is a deviation between what works and what users perceive to work, user education can be used to bridge the gap. To do this, educational goals can be identified. Future work could utilize this dataset as a basis for comparison.

The dataset has demonstrated commonalities and differences across and between different demographic groups. Thus, it provides useful information for those that may be contemplating implementing a news warning system or those that seek to perform future research regarding these systems.

The data presented herein suggest the potential for several key areas of future work. These include the collection of additional data to augment the current understanding with additional demographic groups and respondents from additional geographic locations. There are also a variety of ways that the data could be analyzed in conjunction with other existing datasets and other data that could be collected to further enhance society's understanding of the online deceptive content problem and how to best respond to it. For example, data from testing with actual system interactions could be juxtaposed with the belief and predicted action data presented herein to facilitate analysis of the correlation between beliefs and decision-making. Of course, numerous other potential uses for the data also exist.

Supplementary Materials: The survey instrument is available online at https:/ / www.mdpi.com/ article/10.3390/data7030026/s1.

Author Contributions: Conceptualization, M.S. and J.S.; methodology, M.S. and J.S.; software, R.S., S.H. and R.A.; resources, M.S. and J.S.; data curation, M.S., J.S., R.S., S.H., R.A. and Z.M.; writingoriginal draft preparation, J.S.; writing-review and editing, M.S. and J.S.; supervision, M.S. and J.S.; project administration, M.S. and J.S.; funding acquisition, J.S. All authors have read and agreed to the published version of the manuscript.

Funding: A portion of this research, conducted at North Dakota State University, was supported by the U.S. National Science Foundation (NSF award \# 1757659).

Institutional Review Board Statement: The study was conducted according to the guidelines of the Declaration of Helsinki and approved by the Institutional Review Board of the University of Michigan (HUM00193208), with concurrence by the North Dakota State University IRB.

Informed Consent Statement: Informed consent was obtained from all subjects involved in the study.

Data Availability Statement: The data presented in this study are openly available with the https: / / doi.org/10.17632/9ynrfz24cp.1 under CC-BY-NC-ND license.

Acknowledgments: Thanks is given to Jay Strong for his early work on this project [53], which supported later efforts described herein.

Conflicts of Interest: The authors declare no conflict of interest.

\section{References}

1. Tandoc, E.C.; Lim, Z.W.; Ling, R. Defining “Fake News”. Digit. J. 2018, 6, 137-153. [CrossRef]

2. van der Linden, S.; Panagopoulos, C.; Roozenbeek, J. You are fake news: Political bias in perceptions of fake news. Media Cult. Soc. 2020, 42, 460-470. [CrossRef]

3. Allcott, H.; Gentzkow, M. Social Media and Fake News in the 2016 Election. J. Econ. Perspect. 2017, 31, 211-236. [CrossRef] 
4. Gillin, J. How Pizzagate Went from Fake News to a Real Problem for a DC Business, PolitiFact. 2016. Available online: https:/ /www. politifact.com/article/2016/dec/05/how-pizzagate-went-fake-news-real-problem-dc-busin/ (accessed on 15 November 2021).

5. $\quad$ Lazer, D.M.J.; Baum, M.A.; Benkler, Y.; Berinsky, A.J.; Greenhill, K.M.; Menczer, F.; Metzger, M.J.; Nyhan, B.; Pennycook, G.; Rothschild, D.; et al. The science of fake news. Science 2018, 3, 1094-1096. [CrossRef]

6. Berghel, H. Oh, What a Tangled Web: Russian Hacking, Fake News, and the 2016 US Presidential Election. Computer 2017, 50, 87-91. [CrossRef]

7. Seon-gyu, G.; Ran, L.M. Analysis of Fake News in the 2017 Korean Presidential Election. Asian J. Public Opin. Res. 2020, 8, 105-125.

8. Park, A.; Yourn, K.H. Fake News from a Legal Perspective: The United States and South Korea Compared. Southwest. J. Int. Law 2019, 25, 100.

9. Jankowski, N.W. Researching Fake News: A Selective Examination of Empirical Studies. Javn. Public 2018, 25, 248-255. [CrossRef]

10. Mare, A.; Mabweazara, H.M.; Moyo, D. "Fake News" and Cyber-Propaganda in Sub-Saharan Africa: Recentering the Research Agenda. Afr. J. Stud. 2020, 40, 1-12. [CrossRef]

11. Shao, C.; Ciampaglia, G.L.; Varol, O.; Flammini, A.; Menczer, F. The spread of fake news by social bots. arXiv 2017, arXiv:1707.07592.

12. Lee, T. The global rise of "fake news" and the threat to democratic elections in the USA. Public Adm. Policy 2019, 22, 15-24. [CrossRef]

13. Jin, S.-Y.; Lee, J.-E. The Effect of the Fake News Related to the Electronic Voting System each News Service on News Users' Attitude of Using System, Intention to Participate through System and Reliability of News Services. J. Korea Contents Assoc. 2021, 21, 105-118. [CrossRef]

14. Brashier, N.M.; Schacter, D.L. Aging in an Era of Fake News. Curr. Dir. Psychol. Sci. 2020, 29, 316-323. [CrossRef] [PubMed]

15. Burkhardt, J.M. Chapter 1. History of Fake News. Libr. Technol. Rep. 2017, 53, 5-9. [CrossRef]

16. Albright, J. Welcome to the Era of Fake News. Media Commun. 2017, 5, 87-89. [CrossRef]

17. Tandoc, E.C. The facts of fake news: A research review. Sociol. Compass 2019, 13, e12724. [CrossRef]

18. Leeder, C. How college students evaluate and share "fake news" stories. Libr. Inf. Sci. Res. 2019, 41, 100967. [CrossRef]

19. Marchi, R. With Facebook, Blogs, and Fake News, Teens Reject Journalistic “Objectivity". J. Commun. Inq. 2012, 36, 246-262. [CrossRef]

20. Andorfer, A. Spreading like Wildfire: Solutions for Abating the Fake News Problem on Social Media via Technology Controls and Government Regulation. Hastings Law J. 2017, 69, 1409.

21. Verstraete, M.; Bambauer, D.E.; Bambauer, J.R. Identifying and Countering Fake News. SSRN Electron. J. 2021, 73, 39. [CrossRef]

22. Mayorga, M.W.; Hester, E.B.; Helsel, E.; Ivanov, B.; Sellnow, T.L.; Slovic, P.; Burns, W.J.; Frakes, D. Enhancing public resistance to "fake news". In The Handbook of Applied Communication Research; Wiley \& Sons: Hoboken, NJ, USA, 2020; pp. 197-212. [CrossRef]

23. Clayton, K.; Blair, S.; Busam, J.A.; Forstner, S.; Glance, J.; Green, G.; Kawata, A.; Kovvuri, A.; Martin, J.; Morgan, E.; et al. Real Solutions for Fake News? Measuring the Effectiveness of General Warnings and Fact-Check Tags in Reducing Belief in False Stories on Social Media. Polit. Behav. 2020, 42, 1073-1095. [CrossRef]

24. Spradling, M.; Straub, J.; Strong, J. Introducing \& evaluating "nutrition facts" for online content. In Proceedings of the International Conference on Cyber Security and Protection of Digital Services, Cyber Security, Dublin, Ireland, 15-19 June 2020.

25. Suttle, R.; Hogan, S.; Aumaugher, R.; Spradling, M.; Merrigan, Z.; Straub, J. University Community Members' Perceptions of Labels for Online Media. Future Internet 2021, 13, 281. [CrossRef]

26. Reis, J.C.S.; Correia, A.; Murai, F.; Veloso, A.; Benevenuto, F.; Cambria, E. Supervised Learning for Fake News Detection. IEEE Intell. Syst. 2019, 34, 76-81. [CrossRef]

27. Rehm, G.; Moreno-Schneider, J.; Bourgonje, P. Automatic and manual web annotations in an infrastructure to handle fake news and other online media phenomena. In Proceedings of the Eleventh International Conference on Language Resources and Evaluation, Miyazaki, Japan, 7-12 May 2018.

28. Fuhr, N.; Giachanou, A.; Grefenstette, G.; Gurevych, I.; Hanselowski, A.; Jarvelin, K.; Jones, R.; Liu, Y.; Mothe, J.; Nejdl, W.; et al. An Information Nutritional Label for Online Documents. ACM SIGIR Forum 2018, 51, 46-66. [CrossRef]

29. Tsfati, Y.; Boomgaarden, H.G.; Strömbäck, J.; Vliegenthart, R.; Damstra, A.; Lindgren, E. Causes and consequences of mainstream media dissemination of fake news: Literature review and synthesis. Ann. Int. Commun. Assoc. 2020, 44, 157-173. [CrossRef]

30. Facebook How Is Facebook Addressing False Information through Independent Fact-Checkers? Available online: https://www. facebook.com/help/1952307158131536 (accessed on 6 August 2021).

31. Roth, Y.; Pickles, N. Updating Our Approach to Misleading Information. Available online: https://web.archive.org/web/ 20210806095419/https://blog.twitter.com/en_us/topics/product/2020/updating-our-approach-to-misleading-information (accessed on 6 August 2021).

32. Samek, G. Greater Transparency for Users around News Broadcasters. Available online: https://blog.youtube/news-and-events/ greater-transparency-for-users-around/ (accessed on 6 August 2021).

33. Mena, P. Cleaning Up Social Media: The Effect of Warning Labels on Likelihood of Sharing False News on Facebook. Policy Internet 2019, 12, 165-183. [CrossRef]

34. Gaozhao, D. Flagging fake news on social media: An experimental study of media consumers' identification of fake news. Gov. Inf. Q. 2021, 38, 101591. [CrossRef] 
35. Kim, A.; Moravec, P.L.; Dennis, A.R. Combating Fake News on Social Media with Source Ratings: The Effects of User and Expert Reputation Ratings. J. Manag. Inf. Syst. 2019, 36, 931-968. [CrossRef]

36. Figl, K.; Kießling, S.; Rank, C.; Vakulenko, S. Fake news flags, cognitive dissonance, and the believability of social media posts. In Proceedings of the Fortieth International Conference on Information Systems, Munich, Germany, 15-18 December 2019.

37. Yaqub, W.; Kakhidze, O.; Brockman, M.L.; Memon, N.; Patil, S. Effects of Credibility Indicators on Social Media News Sharing Intent. In Proceedings of the 2020 CHI Conference on Human Factors in Computing Systems, Honolulu, HI, USA, 25-30 April 2020. [CrossRef]

38. Seo, H. Trust It or Not: Effects of Machine-Learning Warnings in Helping Individuals Mitigate Misinformation. In Proceedings of the 10th ACM Conference on Web Science, Boston, MA, USA, 30 June-3 July 2019; Association for Computing Machinery: New York, NY, USA, 2019. [CrossRef]

39. Spradling, M.; Straub, J.; Strong, J. Protection from 'Fake News': The Need for Descriptive Factual Labeling for Online Content. Future Internet 2021, 13, 142. [CrossRef]

40. Motion Picture Association Inc.; National Association of Theatre Owners Inc. Classification and Rating Rules; Motion Picture Association, Inc.: Sherman Oaks, CA, USA; National Association of Theatre Owners, Inc.: Washington, DC, USA, 2020.

41. Welcome to FilmRatings.com. Available online: https://www.filmratings.com/ (accessed on 1 February 2020).

42. The V-Chip: Options to Restrict What Your Children Watch on TV I Federal Communications Commission. Available online: https:/ / www.fcc.gov / consumers / guides/v-chip-putting-restrictions-what-your-children-watch (accessed on 1 February 2020).

43. Geiger, C.J.; Wyse, B.W.; Parent, C.R.M.; Hansen, R.G. Review of nutrition labeling formats. J. Am. Diet. Assoc. 1991, 91, 808-812. [CrossRef]

44. Helfer, P.; Shultz, T.R. The effects of nutrition labeling on consumer food choice: A psychological experiment and computational model. Ann. N. Y. Acad. Sci. 2014, 1331, 174-185. [CrossRef] [PubMed]

45. Besler, H.T.; Buyuktuncer, Z.; Uyar, M.F. Consumer Understanding and Use of Food and Nutrition Labeling in Turkey. J. Nutr. Educ. Behav. 2012, 44, 584-591. [CrossRef] [PubMed]

46. Kim, N.Y.; Lee, J.S. A Study on Perception and Utilization of Food-Nutrition Labeling by Age in Busan residents. J. Korean Soc. Food Sci. Nutr. 2009, 38, 1801-1810. [CrossRef]

47. Huizinga, M.M.; Carlisle, A.J.; Cavanaugh, K.L.; Davis, D.L.; Gregory, R.P.; Schlundt, D.G.; Rothman, R.L. Literacy, Numeracy, and Portion-Size Estimation Skills. Am. J. Prev. Med. 2009, 36, 324-328. [CrossRef]

48. U.S. Food and Drug Administration. Changes to the Nutrition Facts Label. Available online: https://www.fda.gov/food/foodlabeling-nutrition/changes-nutrition-facts-label (accessed on 3 June 2020).

49. U.S. Federal Trade Commission. Concluding Two-Year Rulemaking, FTC Announces New EnergyGuide Label. Available online: https://www.ftc.gov/news-events/press-releases/2007/08/concluding-two-year-rulemaking-ftc-announces-newenergyguide (accessed on 20 February 2022).

50. U.S. Alcohol and Tobacco Tax and Trade Bureau. Wine Labeling: Health Warning Statement. Available online: https://www.ttb. gov / labeling-wine/wine-labeling-health-warning-statement (accessed on 10 January 2022).

51. Data USA. Flint, MI. Available online: https:/ / datausa.io/profile/geo/flint-mi/ (accessed on 7 August 2021).

52. Data USA. Fargo, ND. Available online: https://datausa.io/profile/geo/fargo-nd (accessed on 7 August 2021).

53. Strong, J. Toward Informed News Media Consumption: Avoiding Fake News Via Labelling of Online Content; University of Michigan-Flint: Flint, MI, USA, 2020. 